\title{
Continuous expansion measurement in accelerated concrete prism testing for verifying ASR-expansion models
}

\author{
Wilma Wallau $(\mathbb{D} \cdot$ Stephan Pirskawetz $\cdot$ Katja Voland $\cdot$ Birgit Meng
}

Received: 14 December 2017/ Accepted: 29 May 2018/Published online: 14 June 2018

(C) The Author(s) 2018

\begin{abstract}
The susceptibility of concrete structures due to alkali-silica reaction (ASR) can be assessed by means of ASR concrete prism testing at $60^{\circ} \mathrm{C}$, according to RILEM AAR 4.1. There, expansion of concrete prisms indicates alkali-reactivity of the examined concrete mix. This work applies in situ expansion measurement to accelerated concrete prism testing. Automated measuring facilitates both storage without the usually necessary interruptions for manual measurement and acquisition of quasi-continuous expansion data. A comparative experimental programme showed that conventional testing resulted in stronger expansion and leaching of alkalis than automated testing. Experimental simulation of interruptions, typically associated with manual measurements in conventional testing, could prove the influence of these cooling-heating cycles. Two phenomenological approaches, frequently used for describing reaction kinetics of ASR by linking it to expansion results from ASR-testing, were validated
\end{abstract}

W. Wallau ( $($ ) $)$ S. Pirskawetz $\cdot$ K. Voland · B. Meng Bundesanstalt für Materialforschung und -prüfung, 7.1 Building Materials, Unter den Eichen 87, 12205 Berlin, Germany

e-mail: wilma.wallau@bam.de

Present Address:

K. Voland

Deutscher Beton- und Bautechnik-Verein E.V. (German Society for Concrete and Construction Technology),

Kurfuerstenstrasse 129, 10785 Berlin, Germany with continuous expansion data of three types of aggregate. Experimental expansion depicted s-shaped curves similar to them of the modelling approaches. However, strong swelling recorded in the beginning of the test was not covered by the model curves. Auxiliary measurement of acoustic emissions and ultrasonic velocity helped characterising mechanisms such as hydration and cracking, which also influence prism expansion. The proposed modification of the measurement procedure provides an extended basis to analyse expansion mechanisms. Regarding data for validation of ASR-expansion models, continuous expansion results are preferable to conventional test results.

Keywords Alkali-silica reaction - Accelerated concrete prism test $\cdot$ Automated expansion measurement $\cdot$ ASR modelling

\section{Introduction}

Alkali-silica reaction (ASR) is one of the damaging processes threatening the durability of concrete structures. When aggregates which contain amorphous or semi-crystalline silicates are critically exposed to water and alkali ASR occurs and potentially puts the integrity of a concrete structure at risk. There are various theories on how ASR-damage mechanisms 
occur. However, researchers agree that alkali from the pore solution or external sources, silicate molecules, and water form alkali-silica-reaction-products. These products, often referred to as ASR-gel, require more space than their constituent substances. When the reaction product is exposed to humidity it can swell leading to an additional increase in volume and consequently to a build-up of internal pressures. When the resulting stresses exceed the tensile strength or shear strength of the aggregates or surrounding cement matrix micro-cracking occurs. If such micro-cracks accumulate across a macro-scale concrete component, they evoke degradation and macroscopic expansion of the material [1]. Solution of silicate by the alkaline pore solution is commonly believed to be the basic mechanism when highly reactive aggregate according to class III of RILEM-classification [2] is involved. In these cases, ASR-gel is mainly generated at the surface of the aggregate, the interfacial transition zone between aggregate and cement matrix. Cracks are often filled with relatively large quantities of ASR-gel $[1,3]$. Another type called slow-late reactive aggregates or class II of RILEM-classification [2, 4] is associated with less formation of gel. Cracks originate mostly within the aggregate and expansion of the aggregate leads to micro-cracking of the surrounding cement matrix $[2,4,5]$.

ASR-testing generally aims for the assessment of ASR-damage potential of a concrete mix or a combination of aggregates. There are various testing procedures according to specific national standards and recommendations. Mostly, mortar or concrete samples are exposed to conditions provoking ASR, such as increased availability of alkali and water. Since ASR features large time constants, testing procedures usually specify increased storage temperatures for accelerating the reaction. However, in humid environment temperatures above $65^{\circ} \mathrm{C}$ can promote delayed ettringite formation (DEF), which has a swelling effect on the samples as well [6]. To exclude DEF from possible causes of expansion in ASR-prism testing, storage temperatures are mostly kept below this critical value. For instance the concrete prism tests at 38 and $60{ }^{\circ} \mathrm{C}$ according to the RILEM recommended test methods AAR-3 and AAR-4.1 [4] avoid DEF and are comparatively rapid.

This work focusses on the accelerated ASR-test at $60{ }^{\circ} \mathrm{C}$. Initially, concrete prisms are cast from a specific aggregate applying a partly defined concrete mix. The specimens cure for $24 \pm 2 \mathrm{~h}$ in the mould. After measuring length and mass they are immersed in water for $30 \pm 5 \mathrm{~min}$ and then introduced to testing containers in sets of three. The ASR testing device (reactor), where the containers are stored, guarantees constant conditions of $60 \pm 2{ }^{\circ} \mathrm{C}$ and relative humidity close to $100 \%$. Inside the testing containers a water level of $35 \pm 5 \mathrm{~mm}$ ensures humidities close to saturation as well. During the 5-month test period, measurements are taken regularly every 5 weeks. On this account, the containers need to be withdrawn from the reactor and cooled down to reference temperature. A cool-down phase of $24 \pm 2 \mathrm{~h}$ is appointed to ensure measuring of expansion and mass of the specimens at constant temperature and humidity conditions. Prism expansion is the parameter regarded to indicate the susceptibility of a specific aggregate or a concrete mix to ASR. In this way, test results provide a basis for selection of concretes for a specific building purpose. This approach, its pitfalls and some of the potential are discussed in the following paragraphs.

\subsection{Prism expansion and reaction kinetics}

A fundamental assumption made in concrete prism testing is that there is a relation between the free expansion of the prisms and the damaging effect of ASR. However, prism expansion does not solely depend on the reaction extent but also on other mechanisms. Hydration of the fresh concrete prisms improves the mechanical properties of the concrete matrix. The resistance to internal stress increases throughout the test, which again influences microcracking and thereby macroscopic expansion. Also, pore size distributions in the cement matrix, which depend on hydration, affect transport of alkali, water and reaction product. Further influences are hygroscopic swelling, shrinkage, creep and heat transport. In fact, prism expansion results from highly interrelated processes and mechanisms.

Obviously, elevated temperature, needed for acceleration, increased availability of moisture and alkali influence these mechanisms. Nevertheless, the timedependent prism expansion proved to be linked to the damaging effect of ASR, so that the test method is well established for assessing susceptibility of concrete to ASR. Also, many ASR-modelling approaches infer a time-dependent reaction extent from concrete prism tests. 
In modelling of ASR-induced damage of concrete the definition of the degree of reaction varies from case to case. Often, it describes the rate of generated volume of alkali-silica reaction product (usually referred to as gel) [7]. Ben Haha et al. [8] could demonstrate the existence of such a correlation between expansion results from ASR tests of mortar and concrete prisms and their degrees of reaction obtained from SEM (Scanning Electron Microscope) image analysis. They defined the degree of reaction as the ratio of reacted or cracked and total aggregate surface. Expansion was found to increase with the degree of reaction, first linearly and then declining towards later stages of the reaction, meaning the reaction continues when expansion ceases. Nevertheless, modelling approaches of ASR kinetics mostly suppose a proportional correlation, such as

$\xi(t)=\frac{\epsilon(t)}{\epsilon_{\infty}}$

[9, 10]. This modelling simplification allows for straight forward conversion of expansion $\epsilon(t)$ and asymptotic expansion $\epsilon_{\infty}$ obtained from ASR tests into a reaction extent $\xi(t)$. Expansion curves from ASR tests typically reported depict an initial phase of minor expansion, a second period of increased expansion which is followed by flattening of the curve. For this reason, a phenomenological approach suggested by Larive [10], describing such an s-shape,

$\xi(t)=\frac{1-\mathrm{e}^{-t / \tau_{C}}}{1+\mathrm{e}^{\left(\tau_{L}-t\right) / \tau_{C}}}$

is often applied to model ASR kinetics, with the time constants latency time $\tau_{L}$ and characteristic time $\tau_{C}$, see example curve in Fig. 1.

Based on a comprehensive experimental study, Liu and Mukhopadhyay [11] suggested another expansion approach

$\epsilon=\epsilon_{0} \mathrm{e}^{\left(\frac{\rho}{t-t_{0}}\right)^{\beta}}$.

It describes a different type of s-shape compared to Eq. 2, see Fig. 1. Here, expansion depends upon four parameters instead of three.

By assuming proportionality of macroscopic expansion and reaction kinetics, as well as applicability of such a phenomenological approach, the timedependent reaction-extent $\xi(t)$ is characterised from

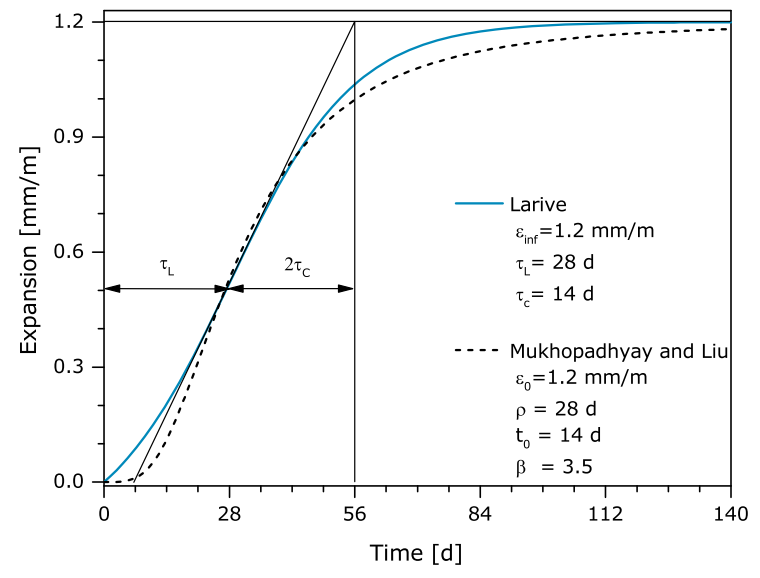

Fig. 1 Example curves of expansion approaches

ASR-test results. This way, ASR-kinetics are described and used as input data for ASR-models on structural level. The mechanical behaviour of concrete structures, meaning elastic expansion and expansion due to micro-cracking, is then modelled separately applying finite element methods [12,13]. As practical experience and experimental work revealed, ASRinduced prism expansion depends on temperature and humidity during storage $[10,14]$. Larive found temperature dependency can be modelled applying the Arrhenius law [10]. Mukhopadhyay and Liu [11], too, include the temperature-dependent rate constant $\beta=f(T)$ to their approach. From a set of expansion data at different temperatures the activation energy can be calculated applying Arrhenius' Law. This compound activation energy is suggested as an alternative criterion to classify ASR-reactivity [11].

Some modelling approaches included availability of water to the kinetics model, more precisely a term of coefficients depending on a degree of water saturation of the pore volume [15-17]. More recently, temperature and humidity dependency was also included to multiphase porous material models [18-20].

Depending on purpose and application, ASR-models vary significantly; for instance in scale, included transport-, reaction-, and damage mechanisms, substances regarded, assumptions, and simplifications. For characterising ASR kinetics, phenomenological approaches are practicable and therefore applied often. Results from laboratory testing, where prisms expand freely, are taken as a reference. This means, the timedependent reaction extent is obtained from expansion 
behaviour of results of accelerated concrete prism testing.

Based on the approach by Larive, concrete expansion in ASR-testing is mostly regarded to happen in three stages: initiation, reaction, and exhaustion. Garcia-Diaz et al. distinguished four instead of three phases [21]. Initially, expansion is absent while silica dissolves (I), then, during a second phase expansive reaction product forms leading to swelling and cracking of the aggregate and global expansion of the specimen (II). While reaction continues and dissolution of silica sets in again in the third phase additional crack volume ought to be filled for further swelling reducing global expansion rate (III). Despite continuing reaction, expansion is asymptotic and reaction product fills cracks in the aggregate within the last phase (IV). On the other hand, Dunant and Scrivener argue that amounts of reaction product would not suffice to completely fill the pores of the cement matrix [22].

\subsection{Influencing factors during testing}

During ASR-storage at $60^{\circ} \mathrm{C}$, a number of interacting, property-changing mechanisms occur simultaneously. Concrete hydrates faster in the hot and humid environment affecting mechanical properties, chemical composition of the pore solution, and pore system. Further, alkali-leaching is a mechanism reported to limit expansion in ASR-testing [23]. Depending on humidity conditions during testing, alkalies leach from the concrete test specimen. At high relative humidity, water vapour condensing on the specimen surface locally reduces the alkali concentration in the pore solution which evokes an alkali transport from the inside of the specimen towards the concrete surface. Alkali-enriched excess water trickles down the surface of the specimens into the water reservoir below. Multon and Sellier [24] explain that low variations of the storage temperature evoke changes of the vapourliquid equilibrium, leading to local condensation and evaporation of water. Leaching of alkali reduces the potential of the reaction and therefore prism expansion. Findings on the influence of temperature on the extent of leaching differ. While some researchers report a clear effect [25], others did not find leaching of alkali to depend significantly on temperature [26]. However, temperature influences the composition of the pore solution, more precisely solubilities of the substances involved, which again affect the reaction mechanism.

Regardless of the exact damage mechanisms presumed, ASR-expansion approaches mostly suppose an asymptotic expansion which is reached within the regular time of ASR testing. Charles-Gibergues and Cyr have carried out accelerated ASR tests at $60{ }^{\circ} \mathrm{C}$ for times much longer than regular storage time, i.e. 7 years [27]. The resulting expansion curves, instead of approaching an asymptotic expansion value, would exhibit an ongoing, approximately linear expansion. The authors assembled similar findings from the literature and questioned that the expansion measured can be ascribed to the damaging effect of alkali-silica reaction only. Additional tests on so-called 'nonreactive' aggregate have been run and, still, exhibited prism expansion. Charles-Gibergues and Cyr regard swelling due to absorption of water during the long time storage in saturated humidity conditions to be a likely cause of expansion. To the knowledge of the authors, the extent had not been quantified so far [27].

Findings on this matter disagree. Some works report asymptotic values whereas others measure ongoing expansion. According to Dunant and Scrivener, flattening of expansion curves during the last phase of testing results from leaching of alkali [22]. While alkali-leaching is a frequently reported problem for laboratory tests [26], it does not occur as severely in real concrete structures [23]. In general, laboratory results are known to differ from expansion measured in field cases, which can be ascribed to differences in dimension and mechanical load [28]. However, ASRtests mostly are criticised for their unrealistic conditions regarding leaching in particular.

An ideal test set-up would guarantee ASR to be the only reason for expansion of the specimens. Regarding interaction of numerous mechanisms (see Sect. 1.1), de-coupling or isolation of a part induced by ASR is barely feasible. Besides general criticism, the test method lacks a technical feature: expansion results at reasonably short time intervals for obtaining a distinct expansion curve.

\subsection{Measuring prism expansion}

In ASR-testing generally the effect of thermal dilatation on prism expansion is excluded by means of the testing procedure itself. In the (German) concrete prism test at $40{ }^{\circ} \mathrm{C}$, a fast measurement at reference 
temperature $20{ }^{\circ} \mathrm{C}$ allows the expansion of the specimens not to be affected by thermal contraction [29]. The situation is different with the accelerated concrete prism test at $60{ }^{\circ} \mathrm{C}$. Here, prior to a measurement, prisms are cooled down to reference temperature for $24 \mathrm{~h}$ inside the containers. This solution brings some drawbacks. First, net time of exposure to reaction promoting elevated temperature is reduced, which can be problematic when measurements are to be run more frequently than every 4 or 5 weeks. Further, during the cooling-heating cycles associated with a manual measurement, temperature and humidity gradients within concrete specimens are believed to be enhancing transport of moisture, alkali, and reaction product. Improved local supply of reactants can have an effect on the reaction. Also, temperature and humidity gradients can directly cause mechanical stresses on the concrete skeleton leading to formation of cracks and macroscopic expansion. These issues limit attempts to increase the number of manual measurements during an ASR-test at $60{ }^{\circ} \mathrm{C}$.

A simple way of improving temporal resolution of the expansion signal and at the same time not interrupting storage is automated in situ expansion measurement. First attempts by Larive successfully applied vibrating wire strain gauges [10] that she embedded into concrete cylinders. Resulting expansion was quasi-continuous and depicted an s-shaped curve, whereas expansion from a comparative test applying manual measurements at a reduced time interval of about 7 day described a first order lag behaviour. Also, asymptotic expansion was found to be lower when testing automatically, which experimentally confirms an effect of interruptions.

Bragg grated optical fibre is another type of embedded sensor, which was used by Dunant to measure strain of ASR-affected cylinders in longitudinal and lateral directions [30]. To avoid leaching, the specimens were kept in an alkaline solution of similar composition as pore solutions.

Instead of embedded solutions, Liu and Mukhopadhyay looked into methods of external expansion measurement. First, an experimental set-up was developed for directly measuring volume expansion of an alkaline solution covering a random packing of aggregate [11]. Based on this, the test set-up was extended also to measure expansions of concrete cylinders [31]. Again, specimens were immersed in alkaline solution at $60{ }^{\circ} \mathrm{C}$ for the entire duration of the test. Increasing the level of alkalinity of the solution has led to greater expansion. The authors listed advantages of this method, such as shortening of the test (49 day) compared with the ASTM C1293 (1 year) and improved reliability due to automated instead of manual measuring, which commonly is affected by uncertainties.

At Bundesanstalt für Materialforschung und prüfung (BAM), Berlin, attempts for continuous measuring in ASR-testing have been very successful in recent years. Automated expansion monitoring could be realised by means of an inductive displacement transducer mounted to a measurement frame. The frame holds standard concrete specimens and is placed inside a testing container [32]. Along with expansion measurement, two supplementary measurement techniques have been applied to characterise expansion and damage mechanisms in ASR-testing, which is acquisition of acoustic emissions and quasicontinuous measuring of ultrasonic velocity [33]. These two auxiliary quantities could help distinguishing three phases in accelerated testing at $60{ }^{\circ} \mathrm{C}$, each characterised by a dominant mechanism: hydration (phase I), crack formation (phase II) and presumed filling of the cracks with ASR product and secondary ettringite (phase III) [34, 35].

This new work now focusses on automated expansion measurement in ASR-testing. Comparative tests aim for evaluation of differences between discontinuous storage (conventional testing) and continuous storage (automated testing). More specifically, effects of selected influence factors, such as the coolingheating cycles associated with manual measurements, the extent of leached alkali and the number of specimens stored per container, are quantified. A second part debates the use of continuous expansion data for validation of the phenomenological ASR expansion models; see Eqs. 2 and 3. Attempts to draw conclusions from continuous expansion results and to better understand mechanisms during storage are supported by auxiliary measurement techniques. By means of simultaneously recorded acoustic emissions and ultrasonic velocities, causes of expansion in ASR concrete prism testing are discussed. 


\section{Experimental procedure}

Based on the RILEM recommended test method AAR4.1 [4], there is a German version of the accelerated concrete prism test at $60{ }^{\circ} \mathrm{C}$ [29], which was applied in this work. Minor differences between the two recommendations concern the concrete mix (cement content), specifications of the grading curve, prism length, casting procedure and the total number of manual measurements. For the experimental programme, concrete prisms $(75 \mathrm{~mm} \times 75 \mathrm{~mm} \times 280 \mathrm{~mm})$ were cast using a CEM I $32.5 \mathrm{R}$ binder with augmented content of alkali ( $\mathrm{Na}_{2}$-equivalent $\left.1.30 \mathrm{wt} \%\right)$, a cement content of $400 \mathrm{~kg} / \mathrm{m}^{3}$ and a water/cement ratio of 0.45 . The sand fraction $(0-2 \mathrm{~mm})$, a non-reactive material, represented 30 vol\% of all aggregates. Small aggregates $(2-8 \mathrm{~mm})$ were $40 \mathrm{vol} \%$, and large aggregates $(8-16 \mathrm{~mm}) 30 \%$. For these fractions $(2-16 \mathrm{~mm})$, three types of aggregate, known from practice to be slowlate reactive: $\mathrm{A}, \mathrm{B}$, and $\mathrm{C}$ were applied. $\mathrm{A}$ is a crushed river gravel, $\mathrm{B}$ a crushed greywacke type, whereas $\mathrm{C}$ designates a natural river gravel. Stainless steel reference studs were embedded centrally in each the of the top and bottom end faces of the prism, serving as points of reference for length measurements.

Curing of the specimens in the moulds lasted $24 \pm 2 \mathrm{~h}$ at $20 \pm 2{ }^{\circ} \mathrm{C}$. To avoid drying, the moulds were covered with damp cloth and plastic sheet. After demoulding, reference measurements of expansion and mass of the prisms were undertaken at reference temperature $(20 \pm 2 \mathrm{C})$. For length change measurement an Invar-rod (280 mm long) served as a reference. Specimens were then immersed in water for $30 \pm 5$ min. Subsequently, control measurements of expansion and mass were run. Three prisms each were put in stainless steel containers over water, which were kept in an ASR-testing reactor to facilitate constant humidity and moisture conditions: $60{ }^{\circ} \mathrm{C}$ and at least $98 \%$ relative humidity. During the 5-month test period, measurements were taken regularly every 28 days. On this account, the containers needed to be withdrawn from the reactor and cooled down to reference temperature in a climatic chamber. A cooldown phase of $24 \pm 2 \mathrm{~h}$ was appointed to ensure measuring of length and mass of the specimens at constant temperature and humidity conditions. If prism expansions exceed $0.3 \mathrm{~mm} / \mathrm{m}$, the aggregate tested is classified as alkali-reactive.
Along with conventional tests applying all three types of aggregate according to the German recommended test method, automated expansion measurements were undertaken. Each measurement was carried out threefold, apart from automated recording of aggregate A-prisms, which was undertaken only twice, since data acquisition of a third system malfunctioned. Different sets of specimens were used for manual measurements. Automated expansion measurement was realised across the prism height by integrating displacement transducers (either eddy current or inductive) to a specimen-fixing rack, see Fig. 2. The counter-part of the sensor was screwed into the top reference stud. The robust sensors from stainless steel function reliably in strongly alkaline environment at saturated humidity and high temperature. The effect of change in temperature on sensor characteristics is below $3 \mu \mathrm{m}$, which, to illustrate the magnitude, is the error tolerated for three subsequent manual length measurements of prisms stored in the same container in the recommended test methods [4, 29].

The $60{ }^{\circ} \mathrm{C}$-concrete prism test regulates vertical orientation of the prisms to be changed after each manual measurement. This procedure is hard to implement in automated expansion measurement, its particular benefits consisting in compliance of storage conditions throughout the whole test and continuous data acquisition. Comparative tests using three

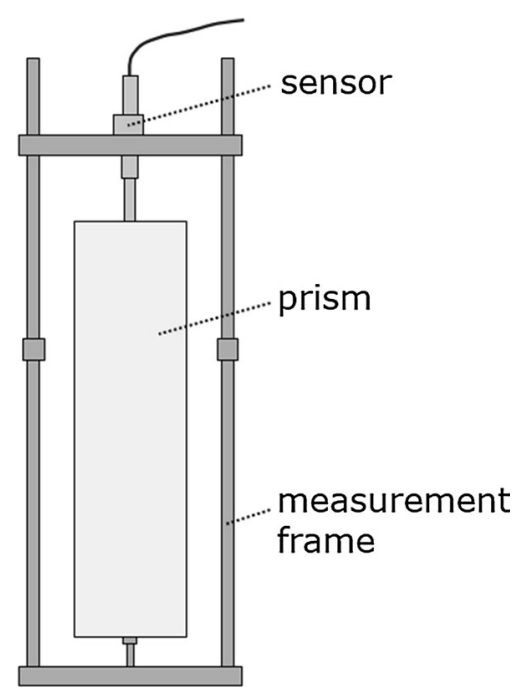

Fig. 2 Automated expansion measurement: specimen-fixing rack with attached eddy current or inductive sensor 
different types of aggregates were run, to assess the effect of omitting changing of vertical orientation of otherwise conventionally tested prisms on expansion. Differences between inverted and non-inverted prisms were in the order of magnitude of the measuring error tolerated in the recommended test methods [4, 29] (3 $\mu \mathrm{m}$ absolute length deviation). Besides, less swelling prisms, with expansion values close to the limit value, show particularly small deviations between inverted and non-inverted prisms. Not meeting the guideline specifications regarding this part of the guideline is thus acceptable.

Along with automated expansion monitoring, complementary acquisition of ultrasonic velocity and acoustic emissions was applied. Damage originating from within brittle materials, such as the formation and growing of cracks, is accompanied by emission of elastic waves. These waves can be detected by piezoelectric sensors coupled to the surface. When coupling several sensors to a specimen, active cracking can be localised by attributing captured signals with individual times of arrival to the same event. Here, two piezoelectric sensors were coupled to the top and bottom surface of the concrete specimens. In this way, acoustic emissions were localised onedimensionally, longitudinally across the prisms. It should be noted that localisation of events occurring in the three-dimensional body is inaccurate. However, it is often used as a tool to reject spurious noise, which cannot be localised within the volume of the prism, from the recorded data set.

For monitoring crack formation in concrete, acoustic emission systems are commonly applied. However, it was applied only seldom for characterising damage processes due to ASR [36-38]. Again, ultrasonic pulse velocity in concrete specimens is commonly measured to characterise ASR-induced damage [1]. Some studies report limited sensitivity of this method and suggest calculation of an acoustic nonlinearity parameter from the measured wave speed and attenuation to obtain more sensitive results [39, 40]. However, $\mathrm{P}$-wave velocities were measured manually every time regular expansion and mass measurements were run at $20^{\circ} \mathrm{C}$ and $65 \%$ r.h. Also, the piezoelectric sensors coupled to the prisms for acoustic emission measurement were used for pulsing ultrasonic signals every hour during storage time. In this way, quasicontinuous signals of the pulse velocity could be generated. Other than in manual measuring, coupling position remains the same, entailing acquisition of a clear propagation when measuring automated.

Furthermore, measurements of $\mathrm{pH}$-value and conductivity of solution at the bottom of ASR-testing containers were undertaken. After the test, a horizontal and a vertical thin section (about $6 \mathrm{~cm} \times 9 \mathrm{~cm}$ ) were prepared from selected continuously stored specimens of each type of aggregate. Analysis of stereo and polarisation microscopic images was undertaken to check for traces of ASR and DEF. The concrete thin sections were impregnated with a fluorescent resin. Stimulation with ultra violet light clearly visualises cracks and pores. Further, for quantification of cracking and comparison between the aggregates, a point counting method was applied to the thin sections of continuously stored prisms. At least 2000 random points per thin section were classified according to their position: aggregate, cement matrix, pore and crack. The number of points located in cracks was related to the total number of points. It statistically quantifies the area of cracks, which characterises the extent of cracking.

\section{Results and discussion}

This paragraph presents and discusses expansion results of conventionally and automatically tested prisms cast from three types of aggregate (A, B and C). Prior to discussion of the recorded expansion data, some issues concerning comparability of the two testing methods must be clarified. One of them is the calculation of expansion $\epsilon(t)=\left(l(t)-l_{0}\right) / L_{0}$ from the measured displacement signal $l(t)$. Two reference values are needed. The initial length $L_{0}$ of the prism is measured prior to the test at $20^{\circ} \mathrm{C}$, like in conventional testing. A reference displacement value $l_{0}=$ $l\left(t_{0}\right)$ representing the start of the test has to be set. Conventional testing requires all measurements to be undertaken at $20{ }^{\circ} \mathrm{C}$ to exclude thermal dilatation whereas automated testing gives a displacement signal corresponding to storage temperature $60{ }^{\circ} \mathrm{C}$. Thus, reference displacement $l_{0}$ must be gathered from the signal, when thermal expansion of frame and prism are completed and thermal equilibrium of the system is attained. Length changes calculated from automated test results then correspond to a conventional test result. At the start of the test, prism and measurement frame are heated from 20 to $60{ }^{\circ} \mathrm{C}$, their thermal 
expansion being reflected by the recorded displacement. The prism reaches storage temperature later than the measurement frame, due to its larger volume and smaller thermal conductivity. Thermocouples were embedded in the centre of concrete prisms, to find the moment of thermal equilibrium. Temperature signals recorded at the start of a test revealed a storage time of $6 \mathrm{~h}$ to be sufficient for the prisms to entirely reach $60 \pm 2{ }^{\circ} \mathrm{C}$. A difference of $6 \mathrm{~h}$ between the start of the test and the beginning of the evaluation interval showed to be appropriate. Shorter durations delivered unreasonably high expansions at the start of the test, leading to misinterpretation.

Applying this approach to calculation, continuous measurement signals of prisms cast from three types of aggregate $\mathrm{A}, \mathrm{B}$, and $\mathrm{C}$ were obtained. These are depicted in Fig. 3 along with according conventional test results for comparison of the testing methods. Already after the first 28 days of storage, the conventional test results reveal that all aggregates are alkalireactive. Microscopic examinations of thin sections prepared from prisms continuously stored showed distinct traces of alkali-silica reaction product and associated cracking for all three types of aggregate. This way ASR was confirmed to be a cause of expansion.

Manual as well as automated measuring exhibit similar deviations between test runs of the same kind of measurement. Further, results confirm findings of decreased expansion when measuring continuously compared with conventional interrupted testing $[10,34]$. However, discontinuous and continuous

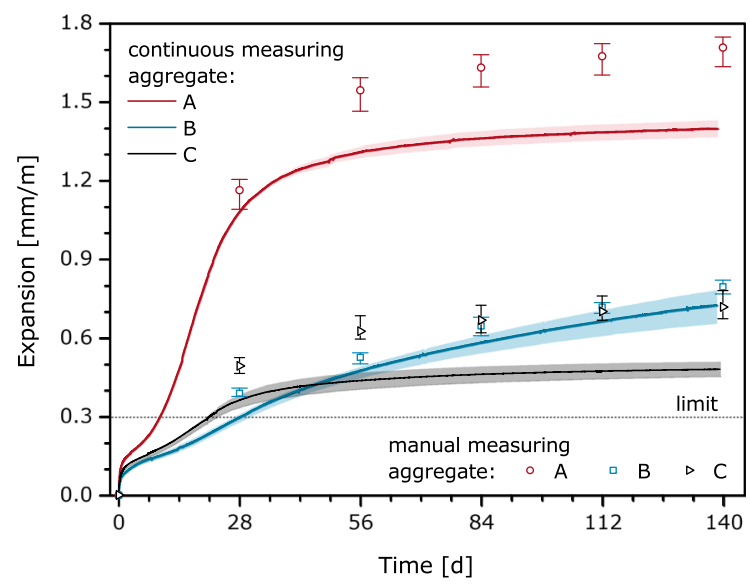

Fig. 3 Expansion from three tested aggregates; mean values and error margin results describe a similar, apparently aggregate-specific shape of the curve.

\subsection{Influencing factors of the testing procedure}

\section{Effect of manual measurement}

In the course of these considerations, the effect of a manual measurement, more specifically the effect of a cooling-heating-cycle, on prism expansion was evaluated experimentally. A container storing three prisms cast from aggregate $A$ was equipped with a frame facilitating automated expansion measurement and placed in a climate cabinet. After 28 days of continuous storage at $60{ }^{\circ} \mathrm{C}$ and up to $100 \%$ relative humidity, the storing temperature was reduced to $20{ }^{\circ} \mathrm{C}$ for $24 \mathrm{~h}$ and then set back to $60{ }^{\circ} \mathrm{C}$. This way, a cooling-heating-cycle could be simulated, even though the containers were not opened to withdraw the prisms for a manual measurement. However, automated expansion measurement was not interrupted allowing insights to prism expansion during the cooling-heating cycle. Two more measurement simulations were run in the progress of the test, at 43 and 77 days, see Fig. 4. This test was only run for a single prism from aggregate A. Cooling of the concrete prisms takes longer than heating due to characteristics of the climate cabinet. Twelve hours suffice for the inside of the prisms to reach cooling temperature. Thermal contractions of the measurement frame, sensor and the concrete prism are staggered and vary in magnitude, which leads to a deviation from the expansion value prior to cool-down. The frame and sensor contract sooner and to a greater extent, letting the prism appear to be expanding. After $12 \mathrm{~h}$ of cooling, when container, sensor, frame and prism have all reached $20^{\circ} \mathrm{C}$, the expansion signal still continues

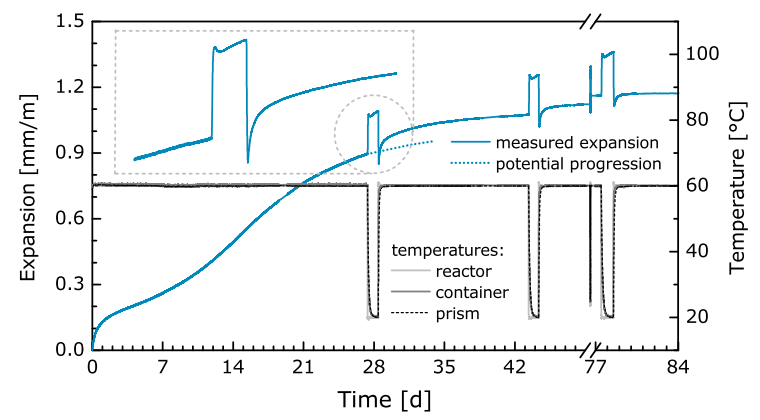

Fig. 4 Temperature and expansion of a prism stored at $60{ }^{\circ} \mathrm{C}$ and repeatedly cooled down to $20{ }^{\circ} \mathrm{C}$ 
to increase. Only reasons other than thermal dilatation can explain the ongoing expansion of the concrete prism. Reducing the storage temperature decreases the absolute humidity inside the container, which leads to a loss of humidity from the prism to the solution in the container. It is possible that, during cooling, temperature gradients accelerate humidity transport and cause a strong loss of humidity, leading to humidity contents below equilibrium content. Once the prisms have reached thermal equilibrium they take-up water again and swell. Eigenstresses induced by temperature and humidity gradients across the specimen can result in formation of micro-cracks and macroscopic expansion during the cooling interval. The interruption clearly enhances the expansion in the subsequent 2-week storage time, which becomes particularly apparent when comparing the signal to a noninterrupted test of specimens also cast from aggregate A (potential progression), see Figs. 3 and 4. The second and third interruption of the test affect the subsequent expansion signal less and less. While the first interruption was undertaken at a point in time when the prism was still expanding, the next two cooling-heating cycles were run when the expansion was already approaching a constant value. Some explanations are conceivable. First, the effect of a cooling-heating cycle enhancing ASR-damage only applies during the phase of significant expansion, when temperature and humidity gradients stimulate transport of pore solution and can thereby evoke improved local allocation of reagents, leading to further ASR-damage. Second, the release of eigenstresses due to temperature and moisture gradients, by formation of micro-cracks along with the first interruption of the test, affects the concrete skeleton most. Whereas following interruptions then evoke less builtup of eigenstresses in the pre-damaged concrete skeleton bringing less additional expansion potential.

These considerations are supported by the results shown in Fig. 3. The first manual expansion measurement gives larger values than the corresponding continuous expansion because the cooling prior to a manual measurement leads to additional expansion. Particularly for aggregate A and C prisms, the third, fourth and fifth manual measurements show less additional expansion than the second does. From the second manual measurement of aggregate B-prisms, deviations between manual and automated expansions are very small, which can be due to slow expansion.
Deviations most likely depend on aggregate specific expansion behaviour.

Further comparative experiments should be undertaken to check for repeatability and quantify the effect of cooling-heating cycles. It remains to be studied in more detail how additional expansion can be explained and how it relates to aggregate type.

\section{Alkali-leaching}

An open question is whether processes of alkalileaching, which are frequently reported to affect expansion in ASR-testing, depend on the type of storage. Chemical analysis of the solution at the bottom of the containers revealed accumulation of sodium, sulfate and most notably potassium. For qualitative characterisation of the process of leaching in continuous and discontinuous storage, $\mathrm{pH}$-value and electrical conductivity of the aqueous solution in the storage containers were being measured during the prescribed measurement every 4 weeks. Accumulation of alkali is reflected in increasing $\mathrm{pH}$, whereas leaching of sulphate reduces $\mathrm{pH}$ of the solution. Electrical conductivity generally increases when alkali and acids accumulate. Regardless of the type of aggregate tested and the number of prisms stored per container, results in Table 1 show that continuously stored prisms leach less than reference prisms, which were tested conventionally. A manual measurement involves a 24-h cool-down of the containers to facilitate measurements at reference temperature $\left(20^{\circ} \mathrm{C}\right)$, and a heating-phase when the containers are being put back into storage after measurement of expansion and mass of the prisms. These coolingheating-cycles entail temperature and moisture

Table 1 Aqueous solution in testing container at the end of testing: increase in conductivity per prism stored and $\mathrm{pH}$-value; automated and conventional testing at varied number of prisms stored per container: 1-aggregate $\mathrm{A}$ and 3-aggregate $\mathrm{C}$

\begin{tabular}{lcl}
\hline Mode of testing & 1 prism (agg. A) & 3 prisms (agg. C) \\
\hline Conductivity increase per prism (mS/cm) & \\
Automated & 5.8 & 2.7 \\
Conventional & 7.8 & 4.4 \\
pH-value at the end of the test & \\
Automated & 11.6 & 12.8 \\
Conventional & 12.8 & 13.0 \\
\hline
\end{tabular}


gradients, intensifying transport of moisture and alkali, which enhance leaching processes. Increased occurrence of micro-cracking, which is particularly associated with cooling-heating-cycles, can further promote leaching due to improved connectivity of the pore and crack volume. From the results, it is not clear whether in automated testing leaching mostly occurs throughout the test or at the end during the cooling interval before measurement of $\mathrm{pH}$ and conductivity. However, it is most obvious that automated testing does mitigate but not completely prevent leaching.

\section{Number of specimens in the container}

It became apparent, that the number of specimens stored per container affects expansion. Alongside conventional tests with three prisms per container, automated and manual measurements of prisms cast from the same aggregate stored by itself in an identical container, for all types of measurement and aggregate, showed, single prisms would expand less. Although two different types of aggregate were tested, Table 1 reveals that single prisms were more strongly affected by leaching. The measured conductivities are referred to the amount of prisms stored per container. Testing only a single prism instead of three means a strong variation of space and geometry inside the container. Additional free volume and air brings more gaseous water. More saturated air circulating inside the container can increase the extent of condensation and subsequent leaching. The findings show that simply following the prescribed casting procedure and providing storage conditions $\left(60{ }^{\circ} \mathrm{C}\right.$ and $\approx 100 \%$ r.h. $)$ does not suffice for ensuring reproducible test results. Instead, standards as for instance the number of prisms to be stored per container should strictly be met.

\subsection{Model validation}

Compared with conventional testing procedures, automated expansion measuring has some crucial benefits. Especially non-interrupted testing at constant conditions and continuous acquisition instead of a few manual measurements are of great benefit for obtaining experimental data for validation of ASR-expansion models. The phenomenological sigmoidal approaches (Fig. 1) resemble the s-shape of experimental results, see Fig. 3, fairly well. On the other hand, all automated expansion signals show the same initial behaviour of a strong increase lasting for about a day after the start of acquisition, see Figs. 3 and 4. This initial expansion is not reflected by the two models.

Generally, the question arises, what particular effects cause such considerable expansion right at the start of the test? ASR-induced damage and expansion is usually regarded to set in with a delay, which will be discussed briefly in Sect. 3.3. Since thermal equilibrium is reached after approximately $6 \mathrm{~h}$ the behaviour cannot be ascribed to thermal expansion either. When starting the test, not more than $26 \mathrm{~h}$ have passed since casting the specimens. Hydration and shrinkage processes are ongoing especially in the beginning. Certainly, shrinkage would appear to diminish the measured expansion. At the start of the test, the slowly heating specimens are exposed to increasing absolute humidity, which can entail absorption of water and hygroscopic swelling. Admittedly, before testing the prisms are immersed in water for $30 \pm 5 \mathrm{~min}$, which should lead to fairly high concentrations of water in the pores. However, saturation will not be reached within this short immersion time and surface drying happens rapidly during the reference measurement and set-up of prism and sensor in the measurement frame. From additional tests applying automated expansion measurement, it became apparent that increased durations between reference measurement and beginning of storage at $60{ }^{\circ} \mathrm{C}$ evoked stronger expansion during the first $24 \mathrm{~h}$ of the test. Within these set-up times of 1 or $2 \mathrm{~h}$, the prisms were mostly kept inside the containers over water at $20^{\circ} \mathrm{C}$. These conditions apparently allowed for drying of the specimens, which, once exposed to testing conditions, have a larger expansion potential due to capillary suction of water. However, even quickest set-up could not circumvent strong expansion at the start. Some inter-dependent mechanisms such as humidity transport, hydration, pore formation and shrinkage influence prism expansion. These considerations should be kept in mind when concluding the reaction extent from expansion signals.

Especially regarding the start of the test, continuous results obtained in this work are not covered by common expansion approaches. For validation of phenomenological modelling approaches, experimental data can be used, when excluding the first $24 \mathrm{~h}$ recorded. Validation, here, was undertaken by fitting the experimental data to both sigmoidal growth approaches 2 and 3 . The two equations fit 
experimental results well, coefficients of determination $R^{2}$ approaching one, see Table 2.

However, the curves in Fig. 5 indicate systematic deviations between experimental results and fits, especially regarding the start of the test. As mentioned above, the initial swelling behaviour measured is not covered by the two equations, which describe simple s-shapes with only a single point of inflection. Also, measured expansion development does not approach an asymptotic expansion value as clearly as suggested by the two model expansion curves, which concurs with findings by Charles-Gibergues and Cyr [27].

Aggregate-specific expansion characteristics are reflected in the fitted parameters. For example, when applying Larive's approach to data of aggregate B and $\mathrm{C}$ prisms, latency times $\tau_{L}$ depict negative values, see Table 2, which means inflection points lie outside the time interval of measurement in third quadrant. This means the relevant part of the fitting curve does not depict an actual s-shape, but only the decelerating part ensuing inflection. In this case, a first order lag approach gives similar fitting accuracy.

Regarding the remarkable variety of expansion curves recorded, the question arises whether there is such thing as a globally applicable expansion curve. Requirements depend on the purpose of modelling. When attempting description of the measured signal, such a phenomenological approach should capture some different swelling characteristics regarding: initial swelling, acceleration and consolidation of expansion and asymptotic as well as ongoing

Table 2 Curve fit data according to model and type of aggregate, see Fig. 5

\begin{tabular}{lccc}
\hline Aggregate & A & B & \\
\hline Larive & & & C \\
$\epsilon_{\infty}$ & 1.24 & 0.76 & 0.38 \\
$\tau_{C}$ & 8.68 & 66.84 & 17.24 \\
$\tau_{L}$ & 16.22 & -126.1 & -2.55 \\
$R^{2}$ & 0.9925 & 0.9987 & 0.9937 \\
Mukhopadhyay and Liu & & \\
$\epsilon_{0}$ & 1.26 & 1.06 & 0.39 \\
$\rho$ & 32.14 & 65.36 & 40.29 \\
$t_{0}$ & -17.68 & -12.22 & -26.97 \\
$\beta$ & 3.55 & 0.85 & 3.11 \\
$R^{2}$ & 0.9980 & 0.9994 & 0.9972 \\
\hline
\end{tabular}

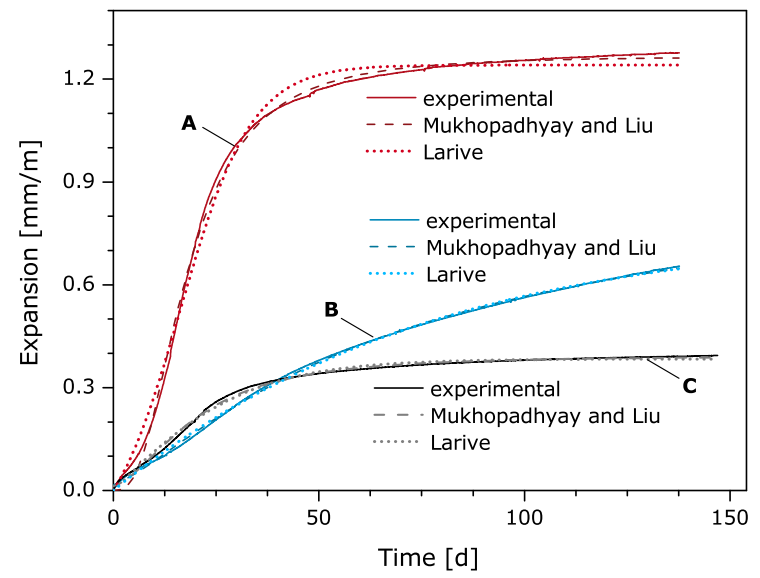

Fig. 5 Curve fits of mean expansion from A, B, and C prisms; applying Eqs. 2 and 3

expansion towards the end of the test. Approaches including temperature-dependency of reaction rates such as in Eqs. 2 and 3 fit experimental results convincingly and serve as input data for macro-scale models. Another prospect of modelling is to help understanding of reaction, transport, damage and expansion mechanisms and to develop a comprehensive model. Mostly, validation of such models is challenging since parameters, such as swelling pressure, concentration of reactants and fracture, can hardly be measured reliably and spatially resolved.

\subsection{Holistic monitoring}

However, there are chances to characterise damage and hydration experimentally by acquisition of acoustic emissions and ultrasonic velocity. Along with continuous expansion data, Fig. 6 depicts acoustic emissions (hits) occurring within twelve hour intervals and the change of ultrasonic velocity since the start of evaluation for measurements of prisms from aggregate A. In the beginning, ultrasonic velocity increases strongly to a local maximum (phase I). Assuming correlation of ultrasonic velocity and dynamic E-modulus $E_{\mathrm{dyn}} \sim v_{\mathrm{US}}^{2}$, this behaviour signifies hydration of the young concrete samples in moist and hot climate conditions, when strength develops with formation of calcium silicate hydrate. Acoustic activity right at the start of storage is due to adaptation of the specimen and measurement system to storage conditions. The number of hits then steadies down throughout this first phase. After that, acoustic emissions accumulate and 


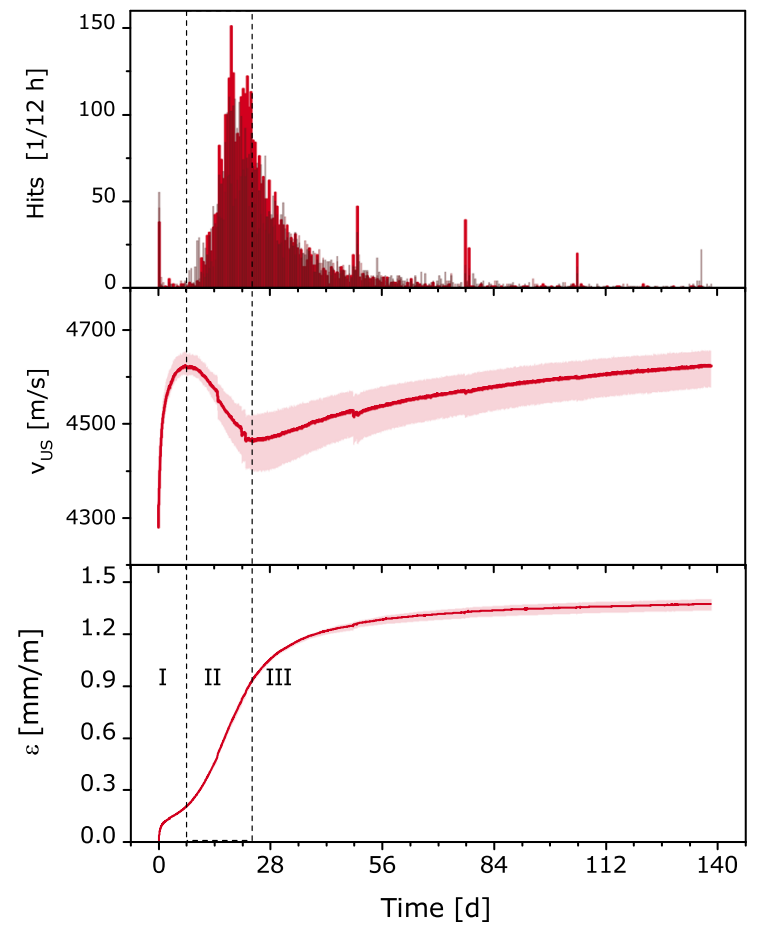

Fig. 6 Acoustic emissions, ultrasonic velocity and expansion of prisms from aggregate $\mathrm{A}$; mean values and error margin

ultrasonic velocities decrease simultaneously. Both denote formation of cracks, which causes accelerated expansion during this second phase. A third phase can be identified during which the acoustic emission activity fades away. Occasional peaks occur when the reactor is opened to withdraw or add other containers. During this third phase expansion flattens out and ultrasonic velocity increases again. Filling of the pores and cracks with reaction product or secondary ettringite would improve wave propagation. Also, cracking can bring better local availability of water leading to hydration of so far non-reacted cement particles and an increased content of moisture. Ultrasonic waves generally propagate better in moist than in dry concrete.

Acoustic emissions and ultrasonic velocities of prisms cast from aggregate $\mathrm{B}$ and $\mathrm{C}$ were also recorded. Figure 7 depicts the results, with $\Delta v_{\text {us }}$ denoting the change in ultrasonic velocity since the start of the test. Aggregate $\mathrm{C}$ prisms showed a similar behaviour as aggregate A prisms (see Fig. 6) only with a less distinct phase of crack formation, meaning fewer acoustic emissions and less of a decline regarding ultrasonic velocity. These results concur

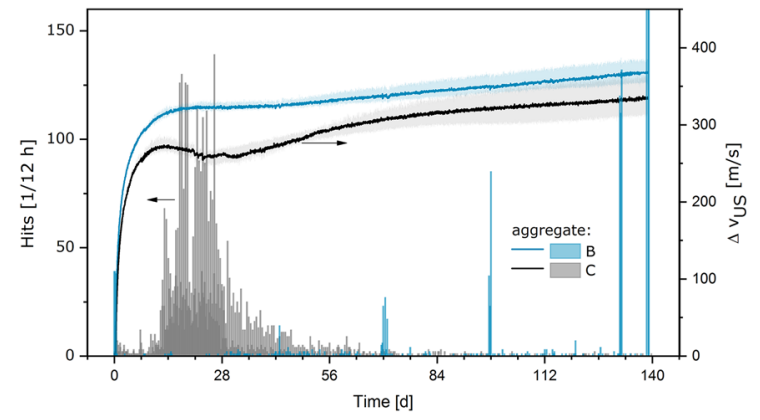

Fig. 7 Acoustic emissions and change of ultrasonic velocities of prisms from aggregate $\mathrm{B}$ and $\mathrm{C}$

with smaller expansion of the prisms compared to aggregate A prisms, see Fig. 3. Prisms from aggregate $\mathrm{B}$, on the other hand, showed no significant accumulation of acoustic emissions. The recorded ultrasonic velocities indicate that B prisms never undergo phase II. After a strong increase of ultrasonic velocity during the hydration phase it does not decrease but temporarily reaches a constant value before changing to phase III, meaning a slight increase.

Cracking can be quantified by acquisition of acoustic emissions and by applying a point counting method to thin sections taken after testing. The evaluated shares of cracked area of the thin sections differ depending on the type of aggregate, see Fig. 8. Details of the thin sections are depicted in the same figure for illustration. For improved vividness the fluorescence images were inverted, thus cracks appear dark. Thin sections from prisms cast from aggregate $\mathrm{B}$ depict the smallest area, aggregate $\mathrm{C}$ thin sections show an increased share of cracked area, and aggregate A thin sections exhibit the largest share. These results correlate with the acoustic activities measured, which also strongly depend on the type of aggregate.

Expansion of prisms is commonly believed to be associated to formation of cracks. Experimental results of aggregate $\mathrm{A}$ and $\mathrm{C}$ support this understanding. It should be noted that stronger expansion does not necessarily coincide with increased occurrence of cracking. Despite little acoustic activity and a relatively small area associated to cracks, prisms from aggregate B expand notably and exceed the limit value. 
Fig. 8 Area associated to cracking, evaluated by point counting of two thin sections of prisms from aggregate $\mathrm{A}$, $\mathrm{B}$ and $\mathrm{C}$; with images revealing cracks for illustration

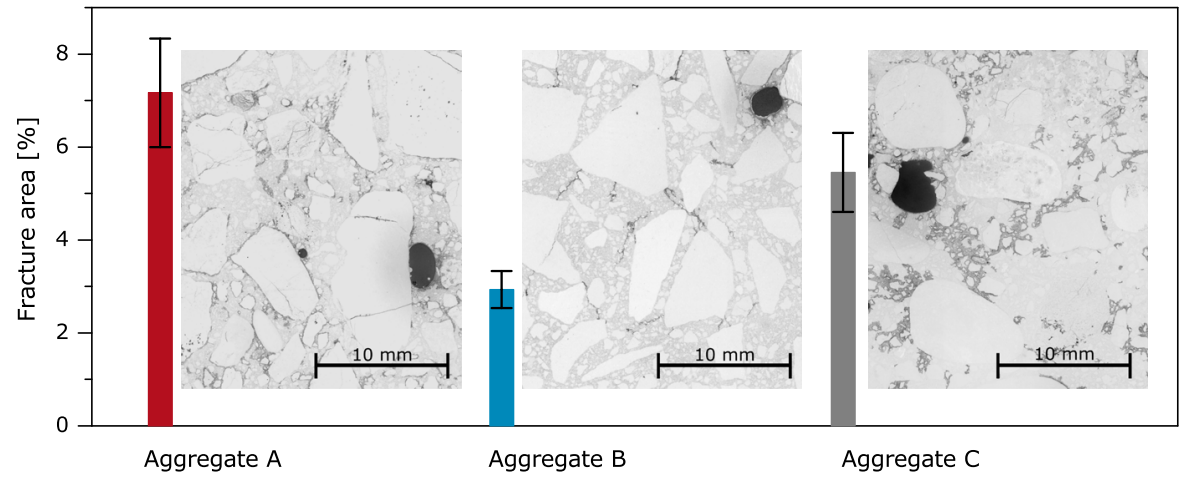

\section{Conclusions}

The experimental results of this research show consistent differences between conventional interrupted and automated continuous ASR testing at $60{ }^{\circ} \mathrm{C}$. On the basis of these findings and results from some supplementary experiments, conclusions with relevance for ASR-testing recommendations can be drawn. They are summarised in the following.

- In concrete prism testing at $60{ }^{\circ} \mathrm{C}$, the expansion is measured manually, regularly throughout the test. This work shows that the cooling-heating cycles, associated to manual measurements, effect additional expansion of the prisms, especially when undertaken during the phase of accelerated expansion. Supplementary tests are needed to quantify the effect of cooling-heating-cycles on the basis of more experimental data.

- Automated expansion measuring can contribute to improving validity of ASR-testing by excluding additional causes of expansion. When aiming for application of automated expansion measurement to ASR-testing at $60{ }^{\circ} \mathrm{C}$, the systematic difference between the expansion values measured in automated and conventional ASR-testing suggests a need for adjustment of the limit value. Roundrobin tests would be an appropriate tool to evolve such a limit value.

- Advantages of automated measuring in ASRtesting include online monitoring, early notice when expansions exceed the limit value and reduced human influence on the test result.

- It became apparent that omitting a change of vertical prism orientation with each manual measurement does not have a significant effect on prism expansion, whereas the number of prisms stored per container does influence leaching and expansion notably.

- Furthermore, conventionally tested prisms are more strongly affected by leaching of alkali than continuously stored prisms in automated testing. However, automated testing most likely cannot completely circumvent leaching.

- Questions regarding transferability of the mechanisms studied at accelerating conditions $\left(60{ }^{\circ} \mathrm{C}\right.$ and $\mathrm{rh} \approx 100 \%$ ) to the mechanisms in real structures or at other ASR-promoting conditions (i.e. 38 or $80^{\circ} \mathrm{C}$ ) remain to be addressed.

- It does not appear worthwhile to recommend acquisition of ultrasonic velocity and acoustic emissions for compulsory application in ASRtesting, since they rise complexity, can be very expensive and require trained operating personnel.

Not only ASR-testing procedures can benefit from automated expansion measurement, continuous expansion data can also contribute to model development, model validation and to understanding of expansion mechanisms. Some relevant aspects are compiled below.

- Two phenomenological ASR-expansion approaches were compared with continuous experimental data. They serve reasonably well for mathematical description of the measured curves. However, the expansion behaviour at the start of the test (first $24 \mathrm{~h}$ ) is not covered.

- For the purpose of ASR-model validation, automated expansion results are generally preferable since cooling-heating-cycles can be evaded applying in situ measurement.

- So far, exact mechanisms cannot be concluded from the expansion curves measured. More 
comprehensive test series applying automated expansion measurement would help identifying the effect of various input parameters such as grading curve, alkali content, temperature, pore size distribution, type of aggregate and water supply. Deeper understanding of relevant hydration, transport, reaction, stress, strain and fracture mechanisms, as well as their coupling effects, is desirable for model development. Also, it could help designing future ASR-test methods and development of counter-measures to avoid ASRdamage in concrete structures.

- Concurrent measuring of ultrasonic velocity and acoustic emissions helps identifying processes of hydration and damage.

- In future research, online monitoring of prism mass could help identifying phases of water intake during storage.

- Further research is required for elaborating to what extent the additional information gained by continuous expansion measurement allows for a deeper characterisation including a better prediction of expansion behaviour and inference on reaction kinetics.

Acknowledgements This study was funded by the MNPQprogramme of the German Federal Ministry for Economic Affairs and Energy (Grant Number 19/14). The authors declare that they have no conflict of interest. The authors like to thank Daniel Werner for analysing microscopy images and Philipp Drabetzki for supporting point counting.

Open Access This article is distributed under the terms of the Creative Commons Attribution 4.0 International License (http:// creativecommons.org/licenses/by/4.0/), which permits unrestricted use, distribution, and reproduction in any medium, provided you give appropriate credit to the original author(s) and the source, provide a link to the Creative Commons license, and indicate if changes were made.

\section{References}

1. Swamy RN (2002) The alkali-silica reaction in concrete. CRC Press, Boca Raton

2. Fernandes I, dos Anjos Ribeiro M, Broekmans MA, Sims I (2016) Petrographic atlas: characterisation of aggregates regarding potential reactivity to alkalis: RILEM TC 219-ACS recommended guidance AAR-1.2, for use with the RILEM AAR-1.1 petrographic examination method, vol 20. Springer, Berlin
3. Werner D, Gardei A, Simon S, Meng B (2015) Microscopic investigations of building materials affected by alkali-silica reaction. In: 15th Euroseminar on microscopy applied to building materials

4. Nixon PJ, Sims I (2016) RILEM recommendations for the prevention of damage by alkali-aggregate reactions in new concrete structures. RILEM state-of-the-art report. Springer, Dordrecht

5. Blight GE, Alexander MG (2011) Alkali-aggregate reaction and structural damage to concrete: engineering assessment, repair and management. CRC Press, Boca Raton

6. Brunetaud X, Linder R, Divet L, Duragrin D, Damidot D (2007) Effect of curing conditions and concrete mix design on the expansion generated by delayed ettringite formation. Mater Struct 40(6):567

7. Huang MS, Pietruszczak S (1999) Modeling of thermomechanical effects of alkali-silica reaction. J Eng Mech ASCE 125(4):476

8. Ben Haha M, Gallucci E, Guidoum A, Scrivener KL (2007) Relation of expansion due to alkali silica reaction to the degree of reaction measured by SEM image analysis. Cem Concr Res 37(8):1206

9. Capra B, Bournazel JP (1998) Modeling of induced mechanical effects of alkali-aggregate reactions. Cem Concr Res 28(2):251

10. Larive C (1997) Apports combinés de l'expérimentation et de la modélisation la compréhension de l'alcali-réaction et de ses effets mécaniques. Ph.D. thesis

11. Liu KW, Mukhopadhyay AK (2014) A kinetic-based ASR aggregate classification system. Constr Build Mater 68:525

12. Saouma V, Perotti L (2006) Constitutive model for alkaliaggregate reactions. ACI Mater J 103(3):194

13. Ulm FJ, Coussy O, Kefei L, Larive C (2000) Thermochemo-mechanics of ASR expansion in concrete structures. J Eng Mech 126(3):233

14. Lindgård J, Sellevold EJ, Thomas MDA, Pedersen B, Justnes H, Rønning TF (2013) Alkali-silica reaction (ASR)performance testing: influence of specimen pre-treatment, exposure conditions and prism size on concrete porosity, moisture state and transport properties. Cem Concr Res 53:145

15. Steffens A, Li KF, Coussy O (2003) Aging approach to water effect on alkali-silica reaction degradation of structures. J Eng Mech ASCE 129(1):50

16. Poyet S, Sellier A, Capra B, Thèvenin-Foray G, Torrenti JM, Tournier-Cognon H, Bourdarot E (2006) Influence of water on alkali-silica reaction: experimental study and numerical simulations. J Mater Civ Eng 18(4):588

17. Martin RP, Metalssi OO, Toutlemonde F (2013) Importance of considering the coupling between transfer properties, alkali leaching and expansion in the modelling of concrete beams affected by internal swelling reactions. Constr Build Mater 49:23

18. Comi C, Kirchmayr B, Pignatelli R (2012) Two-phase damage modeling of concrete affected by alkali-silica reaction under variable temperature and humidity conditions. Int J Solids Struct 49(23-24):3367

19. Pesavento F, Gawin D, Wyrzykowski M, Schrefler BA, Simoni L (2012) Modeling alkali-silica reaction in nonisothermal, partially saturated cement based materials. Comput Methods Appl Mech Eng 225:95 
20. Wu T, Temizer I, Wriggers P (2014) Multiscale hydrothermo-chemo-mechanical coupling: application to alkalisilica reaction. Comput Mater Sci 84:381

21. Garcia-Diaz E, Riche J, Bulteel D, Vernet C (2006) Mechanism of damage for the alkali-silica reaction. Cem Concr Res 36(2):395

22. Dunant CF, Scrivener KL (2016) Physically based models to study the alkali-silica reaction. Proc Inst Civ Eng Constr Mater 169(3):136

23. Rivard P, Bérubé MA, Ollivier JP, Ballivy G (2007) Decrease of pore solution alkalinity in concrete tested for alkali-silica reaction. Mater Struct 40(9):909

24. Multon S, Sellier A (2016) Multi-scale analysis of alkalisilica reaction (ASR): impact of alkali leaching on scale effects affecting expansion tests. Cem Concr Res 81:122

25. Ideker JH, East BL, Folliard KJ, Thomas MDA, Fournier B (2010) The current state of the accelerated concrete prism test. Cem Concr Res 40(4):550

26. Lindgård J, Thomas MDA, Sellevold EJ, Pedersen B, Andiç-Çakır O, Justnes H, Rønning TF (2013) Alkali-silica reaction (ASR)-performance testing: influence of specimen pre-treatment, exposure conditions and prism size on concrete porosity, moisture state and transport properties. Cem Concr Res 53:68

27. Carles-Gibergues A, Cyr M (2002) Interpretation of expansion curves of concrete subjected to accelerated alkali-aggregate reaction (AAR) tests. Cem Concr Res 32(5):691

28. Giorla AB, Scrivener KL, Dunant CF (2015) Influence of visco-elasticity on the stress development induced by alkali-silica reaction. Cem Concr Res 70:1

29. DAfStb-Richtlinie Vorbeugende Maßnahmen gegen schädigende Alkalireaktion im Beton (Alkali-Richtlinie). Tech. rep., Deutscher Ausschuss für Stahlbeton (2013)

30. Dunant C (2009) Experimental and modelling study of the alkali-silica reaction in concrete. Ph.D. thesis

31. Mukhopadhyay AK, Liu KW (2016) A kinetic-based ASR aggregate classification system. In: Transportation research board 95th annual meeting
32. Weise F, Pirskawetz S, Maier B,Voland K (2010) Kontinuierliche Dehnungsmessung bei Prüfung des Einflusses der Alkali-Kieselsäure-Reaktion auf Gefügeveränderungen in Betonen, Patent (DE 102010017468 B4, EP 2397848 A1)

33. Weise F, Pirskawetz S, Maier B, Voland K (2010) Messeinrichtung und Messverfahren zur Alkali-KieselsäureReaktion in Betonen mittels kontinuierlicher Schallemissionsanalyse und Ultraschallmessung, Patent (DE 102010017466 B4, EP 2397849 A1)

34. Voland K (2015) Einfluss der Porosität von Beton auf den Ablauf einer schädigenden Alkali-Kieselsäure-Reaktion. Ph.D. thesis

35. Weise F, Voland K, Pirskawetz S, Meinel D (2012) Innovative measurement techniques for characterising internal damage processes in concrete due to ASR. In: 14th international conference on alkali aggregate reaction

36. Pour-Ghaz M, Spragg R, Castro J, Weiss J (2012) Can acoustic emission be used to detect alkali-silica reaction earlier than length change tests? In: Proceeding of the 14th international conference on alkali-aggregate reaction in concrete

37. Abdelrahman M, ElBatanouny MK, Ziehl P, Fasl J, Larosche CJ, Fraczek J (2015) Classification of alkali-silica reaction damage using acoustic emission: a proof-of-concept study. Constr Build Mater 95:406

38. Lokajíček T, Přikryl R, Šachlová S, Kuchařová A (2017) Acoustic emission monitoring of crack formation during alkali silica reactivity accelerated mortar bar test. Eng Geol 220:175

39. Sargolzahi M, Kodjo SA, Rivard P, Rhazi J (2010) Effectiveness of nondestructive testing for the evaluation of alkali-silica reaction in concrete. Constr Build Mater 24(8): 1398

40. Ju TH, Achenbach JD, Jacobs LJ, Guimaraes M, Qu JM (2017) Ultrasonic nondestructive evaluation of alkali-silica reaction damage in concrete prism samples. Mater. Struct. 50(1):60 